\title{
The Effect of Umbilical Cord-derived Mesenchymal Stem Cell Transplantation in a Patient with Cerebral Palsy: A Case Report
}

\author{
Sibel Çağlar Okur ${ }^{1}$, Sinan Erdoğan ${ }^{2}$, Cansu Subaşı Demir ${ }^{3}$, Gülşen Günel ${ }^{3}$, Erdal Karaöz ${ }^{2,3,4}$ \\ ${ }^{1}$ Department of Physical Therapy and Rehab, Health Science University, \\ Bakirköy Dr Sadi Konuk Training and Research Hospital, Istanbul, Turkey \\ ${ }^{2}$ Department of Histology and Embryology, Istinye University, Faculty of Medicine, Istanbul, Turkey \\ ${ }^{3}$ Center for Stem Cell and Tissue Engineering Research and Practice, İstinye University, İstanbul, Turkey \\ ${ }^{4}$ Center for Regenerative Medicine and Stem Cell Manufacturing (LivMedCell), Liv Hospital, İstanbul, Turkey
}

Background: Cerebral Palsy (CP) is the most common motor disability reason of childhood that occurs secondarily to non-progressive damage in the brain whose development is still ongoing.

Methods: 6-year-old dystonic-spastic male CP patient received allogenic mesenchymal stem cells treatment four times as $1 \times 10^{6} / \mathrm{kg}$ in intrathecal and intravenous administration of Umbilical Cord-derived mesenchymal stem cells (UC-MSCs) ways. Before and after the treatment, the patient was followed-up with FIM (Functional Independent Measurement), GMFCS (Gross Motor Function Classification System 88), Tardieu Scale, TCMS (Trunk Control Measurement Scale), MACS (Manual Ability Classification Scale), CFSS (Communication Function Classification System) for 18 months and received intensive rehabilitation.

Results: Improvements were observed especially in functional scales except for the Tardieu Scale, and no adverse effects were detected aside from a slight pain in the back.

Conclusion: Wider future case studies on UC-MSCs will enable us to assess the efficacy of UC-MSCs which have positive impacts especially on functional scales.

Keywords: Cerebral palsy, Mesenchymal stem cell, Rehabilitation

Received: December 30, 2017, Revised: April, 5 2018,

Accepted: April 13, 2018, Published online: April 30, 2018

Correspondence to Sibel Çağlar Okur

Department of Physical Medicine and Rehabilitation, Ministry of Health Dr. Sadi Konuk Education and Research Hospital, Zuhuratbaba Mah, Tevfik Sağlam Cad No:11, 34147 Bakırköy, Istanbul, Turkey

Tel: +90-533-3365651, Fax: +90-212-542-4491

E-mail: sibelcaglarokur@gmail.com

(a) This is an open-access article distributed under the terms of the Creative Commons Attribution Non-Commercial License (http://creativecommons.org/ licenses/by-nc/4.0/), which permits unrestricted non-commercial use, distribution, and reproduction in any medium, provided the original work is properly cited.

Copyright (c) 2018 by the Korean Society for Stem Cell Research

\section{Introduction}

Non-progressive lesions in the brain cause Cerebral Palsy. There might be functional disabilities in children with $\mathrm{CP}$ and periventricular leukomalacia, intrauterine haemorrhagia; stiffness, contractures, muscle strength weakness, sensory defects, and difficulties in balance and motion control may also be observed (1). Physical therapy, neurectomy, botulinum toxin A and medications may be used in the treatment of CP. It has been reported in several case studies that the above mentioned therapies can improve the functions partially; however, the complete cure cannot be achieved through these interventions (2). It has also been reported in previous studies that in developed countries, 1.5 2.5 children per 1,000 of the total population had Spastic CP; and this rate might be higher 
in developing countries (3). In traumas, inflammations and cerebral diseases, the brain has a relatively low-level renewable capacity i.e. self-repair capacity (4). Animal experiments and clinical studies in recent years have reported positive outcomes in cell transplantation for the treatment of various diseases. The central nervous system may be regenerated with cytotherapy, which is an option that aims to replace the functionally depleted cells because of a traumatic brain injury $(5,6)$. In 1976, Allogenic Mesenchymal Stem Cell treatments were first reported in the stromal compartment of the bone marrow (7). Prior to this development, a few studies had reported positive outcomes of using Mesenchymal Stromal Cells to treat neurological diseases like spinal cord injury and basilar artery dissection $(8,9)$. In recent time, a case study reported that intrathecal infusion of autologous bone marrow mononuclear cells showed that cell transplantation was effective and safe, and had encouraging functional results in a cerebral palsy patient (10). In a traumatic brain injury model, Lee et al. (11) used a combination of stem cell therapy with rehabilitation and reported that recovery results were similar to those when rehabilitation was used alone.

In this case report, we investigated the safety and efficacy of intrathecal, intramuscular and intravenous applications of UC-MSCs in a child with Cerebral Palsy.

\section{Case Presentation}

6-year-old male child patient (30-week, 1918 gr) had dystonic CP which was effective more in the lower extremity than in the upper one. The patient applied to us with intrauterine bleeding. The patient was born with head circumference $28 \mathrm{~cm}$, height $41 \mathrm{~cm}$, after 2-week incubator follow-up, and the brain MRI was performed. The patient was diagnosed with $\mathrm{CP}$, and has been followed-up ever since. The patient has received various medical treatments such as baclofen and rehabilitation and partial benefits were reported.

\section{Patient Assessment Tests}

\section{Functional examination}

Eating, grooming, bathing, upper body dressing, lower body dressing, toileting, bladder, management, bed to chair transfer, toilet transfer, shower transfer, locomotion (ambulatory or wheelchair level), stairs, cognitive comprehension, expression, social interaction, problem solving, memory etc. evaluated with Functional Independent Measurement (FIM) (Table 1) (9). Functional independence was evaluated with scoring ranging from 18 to 126 . Gross Motor Function Classification System 88 (GMFCS) (10) used to determine the observational functional level in children with cerebral palsy.

Table 1. Results of patient assessment tests

\begin{tabular}{|c|c|c|}
\hline & \multicolumn{2}{|c|}{ Followed-up } \\
\hline & Onset & Sixt month after first intervention \\
\hline \multicolumn{3}{|l|}{ Functional examination } \\
\hline Functional Independent Measurement (FIM) & $56 / 126$ & $76 / 126$ \\
\hline $\begin{array}{l}\text { Gross Motor Function Classification System } 88 \\
\text { (GMFCS) }\end{array}$ & $\begin{array}{l}\text { Level } 5 \text { (Carried on a wheelchair } \\
\text { pulled by hands). }\end{array}$ & $\begin{array}{l}\text { Level } 3 \text { (The patient walks by using the } \\
\text { walking aids held by hands). }\end{array}$ \\
\hline \multicolumn{3}{|l|}{ Upper extremity } \\
\hline MACS (Manual Ability Classification Scale) & $\begin{array}{l}\text { Level } 3 \text { (The patient can hold and } \\
\text { use objects with difficulty, preparing } \\
\text { the activities takes time). }\end{array}$ & $\begin{array}{l}\text { Level } 2 \text { (Handles most objects but with } \\
\text { some reduced quality and/or speed) }\end{array}$ \\
\hline \multicolumn{3}{|l|}{ Trunk control and sitting balance Assessment } \\
\hline $\begin{array}{l}\text { Static sitting balance } \\
\text { Dynamic sitting balance }\end{array}$ & $2 / 20$ & $10 / 20$ \\
\hline Selective movement control & $2 / 28$ & $17 / 28$ \\
\hline Dynamic reaching (Equilibrium reactions) & $1 / 10$ & $4 / 10$ \\
\hline Total score & $5 / 58$ & $31 / 58$ \\
\hline \multicolumn{3}{|l|}{ Communication skills } \\
\hline $\begin{array}{l}\text { Communication Function Classification System } \\
\text { (CFSS) }\end{array}$ & $\begin{array}{l}\text { Level } 3 \text { (Effective Sender and Effective } \\
\text { Receiver with familiar partners). }\end{array}$ & $\begin{array}{l}\text { Level } 2 \text { (Receptive and Productive skills } \\
\text { are slow but fluent with familiar and } \\
\text { foreign partners). }\end{array}$ \\
\hline
\end{tabular}




\section{Upper extremity}

In daily life, how children with $\mathrm{CP}$ use their hands was assessed with MACS (Manual Ability Classification Scale) (Table 1) (11). Manual Ability Classification System (MACS) describes how children with cerebral palsy use their hands to handle objects in daily activities. MACS describe five levels. The levels are based on the children's self-initiated ability to handle objects and their need for assistance or adaptation to perform manual activities in every day.

\section{Trunk control and sitting balance assessment}

The sitting balance and functional independency during sitting was assessed with Trunk Control Measurement Scale (TCMS) test (Table 1) (12). Static sitting balance, dynamic sitting balances are considered in the subheadings of selective movement control and dynamic reaching (Equilibrium Reactions). Scoring is done on 58 points.

\section{Lower extremity examination}

Lower extremities were assessed with Modified Tardieu Scale (13). This scale quantifies muscle spasticity by assessing the response of the muscle to stretch applied at specified velocities and the results are listed in Table 2.

\section{Communication skills}

Communication Function Classification System (CFSS) (14) provides 5 levels (CFCS I, II, III, IV, V) to describe everyday communication performance patients with cerebral palsy (Table 1).

The patient had speaking disorder, and had saliva com- ing out of the mouth. The patient also had growth retardation and the family described occasional difficulty in swallowing in solid foods. There was clonus in both feet especially in the left foot. Babinski result was negative. Pendulum test was positive. Thomas bilateral test result was positive.

\section{Procedure}

The clinical trial cases from the Republic of Turkey was approved by the ministry of health departments in organ and tissue transplantation (permission number; 56733164/ 203). The family was informed about all possible consequences and a written consent was received from the family.

The applications were made in surgery conditions by using masque anesthesia.

The intrathecal application was performed through Lumbar 3 4 vertebrae with a 22-Gouge spinal needle. Intravenous application; within 60 minutes, $1 \times 10^{6} \mathrm{cell} / \mathrm{kg}$ was applied (Table 3) in $500 \mathrm{cc}$ isotonic with slow infusion and the patient was followed-up in the hospital for 1 day.

After the applications, the patient was restricted for movements for 2 days, and the family was warned against water contact in the injection areas.

\section{Isolation of MSCs from umbilical cord}

Umbilical cord was obtained from a full-term delivery with informed maternal consent. UC-MSCs were produced at the Good Manufacturing Practice facility of LivMedCell,

Table 2. Tardieu Scale Assessment in lower extremity

\begin{tabular}{|c|c|c|c|c|c|}
\hline MUSCLE & Right/Left & $\mathrm{X} 1$ & SpasticityAngle (R1-R2) 1 & $\mathrm{X} 2$ & SpasticityAngle (R1-R2) 2 \\
\hline \multirow[t]{2}{*}{ Knee Flexors } & Right & 2 & 25 & 2 & 25 \\
\hline & Left & 2 & 35 & 2 & 35 \\
\hline \multirow[t]{2}{*}{ KneeExtensors } & Right & 2 & 5 & 2 & 5 \\
\hline & Left & 2 & 7 & 2 & 7 \\
\hline \multirow[t]{2}{*}{ AnklePlantar Flexor (Gastrocnemius) } & Right & 3 & 25 & 3 & 25 \\
\hline & Left & 3 & 20 & 3 & 20 \\
\hline \multirow[t]{2}{*}{ AnklePlantar Flexor (Soleus) } & Right & 3 & 25 & 3 & 25 \\
\hline & Left & 3 & 20 & 3 & 20 \\
\hline
\end{tabular}

Table 3. Transplantation details

\begin{tabular}{cccc}
\hline Date (year/month/day) & Cell count (intravenous) & Cell count (intrathecal) & Cell viability (\%) \\
\hline $2017 / 03 / 02$ & $15 \times 10^{6}$ & $15 \times 10^{6}$ & 90.20 \\
$2017 / 03 / 17$ & $15 \times 10^{6}$ & $15 \times 10^{6}$ & 90.48 \\
$2017 / 03 / 30$ & $15 \times 10^{6}$ & $15 \times 10^{6}$ & 90.40 \\
$2017 / 04 / 13$ & $15 \times 10^{6}$ & $15 \times 10^{6}$ & 91.20 \\
\hline
\end{tabular}


Istanbul, Turkey. The cord was washed, blood vessels removed and tissue cut into pieces $\left(5 \sim 10 \mathrm{~mm}^{2}\right)$ and cultured in culture plates. The culture expansion of small pieces of tissue is known as the "explants method." The explants were left undisturbed for one week to allow the migration of cells from the margins of explants. After reaching $70 \%$ to $80 \%$ confluency, adherent cells were harvested with trypsinization by $0.05 \%$ trypsin-EDTA (Gibco, Germany). Quality control and quality assurance for the production of these cells at were performed according to the standards of the Turkish Medicines and Medical Devices Agency (TMMDA).

Characterization of UC-MSCs: Flow cytometry analysis of expressed surface antigens showed that these cells were uniformly positive for CD44, CD73, CD105 and CD90 and negative for the hematopoietic lineage markers CD34, CD45 and HLA-DR. MSC analysis kit (cat no:562245) was used for MSC characterization flow cytometry analysis. The
A

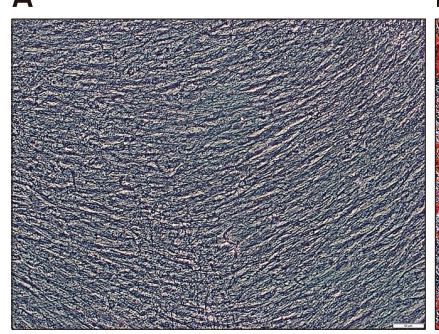

E

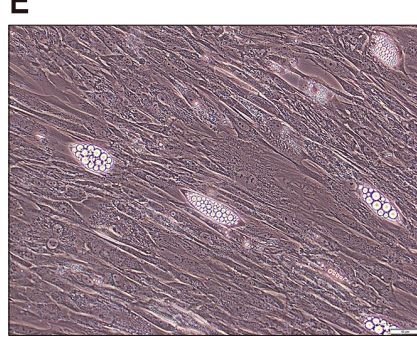

$\mathrm{H}$
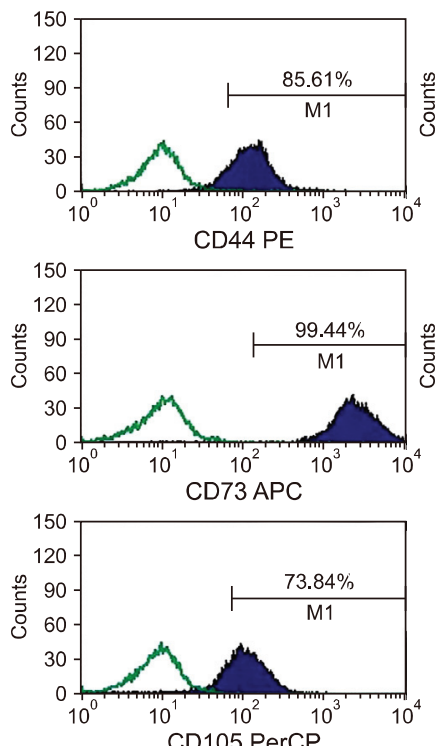

B

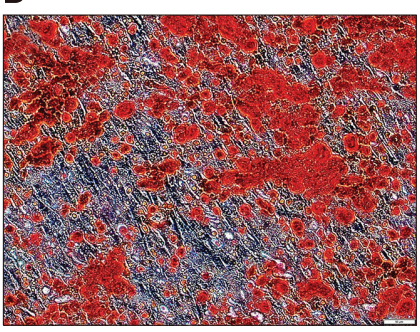

$\mathbf{F}$
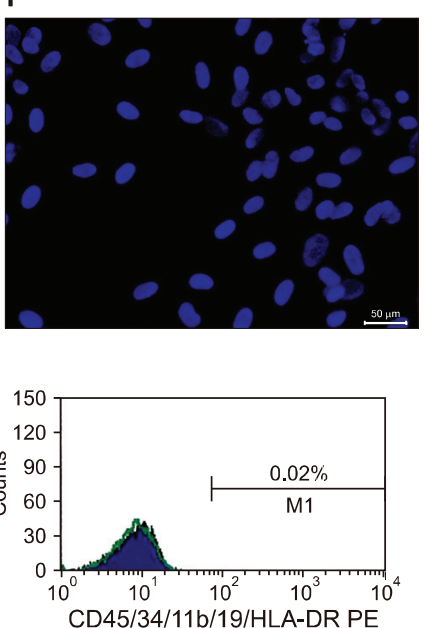

C

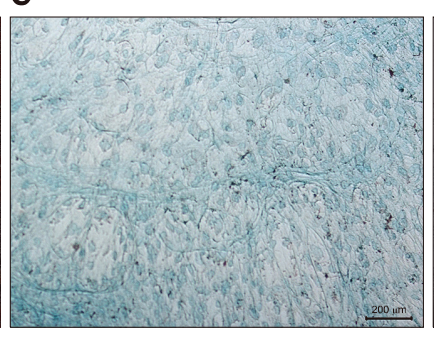

D

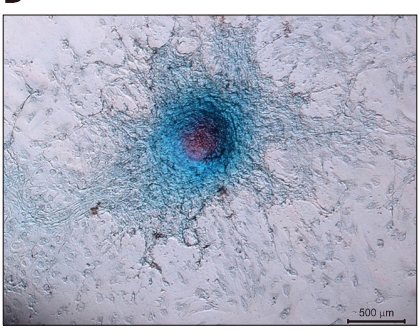

G

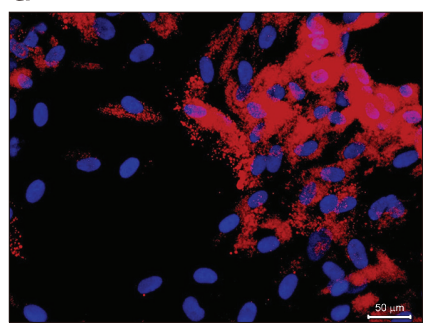

I

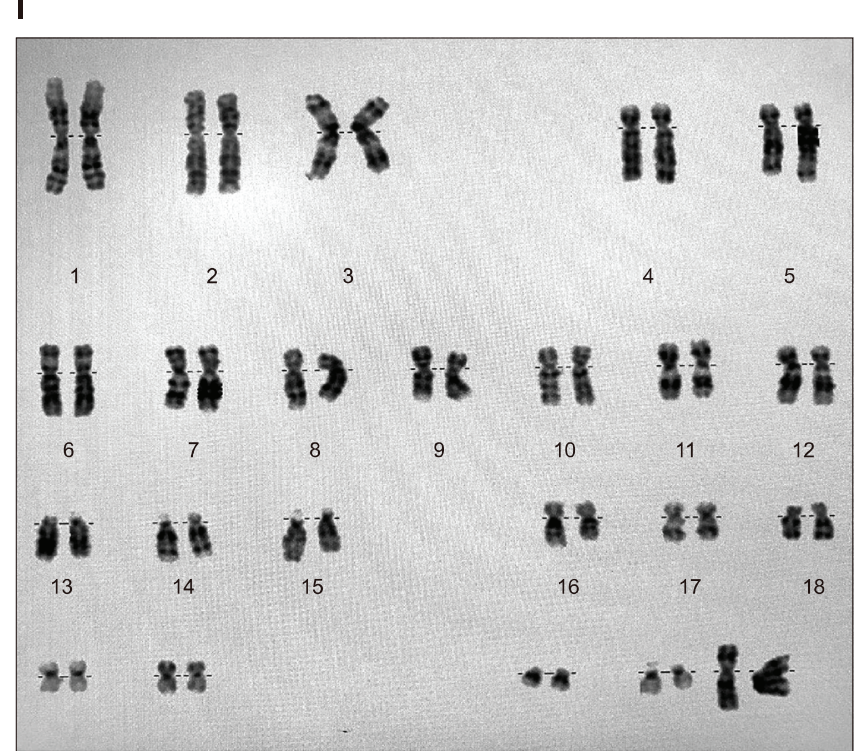

Fig. 1. Characterization and differentiation of UC-MSCs. (A) Osteogenic differentiation control (B) and mineral nodules that stained by Alizarin Red S, of UC-MSCs cultured in osteogenic differentiation medium. (C) Chondrogenic differentiation control (D) and alcian blue staining of UC-MSCs cultured in chondrogenic differentiation medium. (E) Morphology, (F) adipogenic differentiation control and (G) Oil Red O staining of neutral lipid vacuole formation in UC-MSC cultured in adipogenic differentiation medium. (H) Flow cytometric analysis of cell surface markers of UC-MSCs at P3. (I) Chromosome karyotype analysis of the cultered UC-MSCs. 
kit contains control, positive cocktail and negative cocktail antibodies. Human MSCs were characterized by using the following conjugated monoclonal antibody combinations; negative cocktail (CD34 PE, CD19PE, CD45PE, CD11bPE and HLA-DR PE), positive coctail (CD90 FITC, CD44 PE, CD105 PerCP ve CD73 APC). Cells were analyzed on BD FACS Calibur (BD Bioscience, San Jose, CA) by using CellQuest Software program. The expression of negative and positive cocktail antibodies are shown on the histogram plot. Positive cocktail antibodies were analyzed on four histogram plots. Positive cocktail was shown in separate histograms because different color dyes were used for each of the antibodies (CD90 FITC, CD44 PE, CD105 PerCP ve CD73 APC). Negative cocktail antibodies are based on the average highest expression of the five antibodies, if one of the values is positive, the positive area will peak in the graph, so the negative cocktail values were shown on the same histogram plot, passing through the PE detector FL2 (All antibodies used in the negative cocktail are PE-labeled. For this reason, it can be shown on the same histogram). If the expression is high, each antibody is controlled separately. (Fig. 1H).

It has been showed that the telomerase activities of UC-MSCs stay stable during cell culture procedures (Data not shown). The expressions of some stem cell and differentiation markers such as TERT, POU5F1, SOX2, ZFP42, CD44, VCAM1, THY1, BMP2, RUNX-1, VIM, ICAM1, NES were determined (Data not shown). No structural or numerical chromosomal abnormalities were found in karyotype analyses of the cells (Fig. 1I).

The final UC-MSCs preparations used in the infusion were harvested from cell culture passage 3 and suspended at final densities that are $15 \times 10^{6} / 3 \mathrm{ml}$ and $15 \times 10^{6} / 20 \mathrm{ml}$ in normal saline.

\section{In vitro differentiation of UC-MSCs}

To induce adipogenic differentiation, cells were seeded onto six-well plates (P3; 3000 cells $/ \mathrm{cm}^{2}$ ) and cultured with Mesencult MSC Basal Medium (StemCell Technologies Inc, Vancouver, BC, Canada) supplemented with 10\% adipogenic supplement and $1 \%$ penicillin/streptomycin for 3 weeks. The medium was refreshed every $3 \sim 4$ days. The formation of intracellular lipid droplets (Fig. 1E), which indicates adipogenic differentiation, was confirmed by staining with $0.5 \%$ oil red O (Sigma-Aldrich) (Fig. 1F, G).

For osteogenic differentiation, cells (P3; 3000 cells $\left./ \mathrm{cm}^{2}\right)$ were seeded on collagen-precoated (type I) coverslips in six-well plates. The differentiation medium composed of LDMEM supplemented with dexamethasone $(0.1 \mathrm{mmol} / \mathrm{L}$; Sigma-Aldrich), ascorbate-2-phosphate $(0.05 \mathrm{mmol} / \mathrm{L}$;
Wako Chemicals, Richmond, VA), $\beta$-glycerophosphate (10 mmol/L; Sigma-Aldrich), primocin (2\%; Invitrogen) and FBS (10\%; Gibco/Life Sciences). Medium was refreshed twice a week. After four weeks, osteogenic differentiation was estimated by alizarin red staining. For Alizarin red staining, cells were fixed for $5 \mathrm{~min}$ in ice-cold $70 \%$ ethanol. The cells were stained with alizarin red solution (2\%, pH 4.2) (Fig. 1A, B). Stained cells were dehydrated in pure acetone, fixed in acetone-xylene (1:1) solution and cleared with xylene.

For chondrogenic differentiation; MSCs isolated from the umbilical cord were induced in the following chondrogenic medium: DMEM, supplemented with 10\% FBS, 2 $\mathrm{mM}$ L-glutamine, $50 \mu \mathrm{g} / \mathrm{ml}$ penicillin-streptomycin, 50 $\mu \mathrm{g} / \mathrm{ml}$ ascorbic acid and $1 \mathrm{ng} / \mathrm{ml}$ human recombinant transforming growth factor $\beta 1$ (TGF- $\beta 1$ ). The differentiated cells were stained with alcian blue solution (Fig. $1 \mathrm{C}, \mathrm{D})$.

\section{Rehabilitation program}

As of the 3rd day of the application, intense physiotherapy and exercise program was started with the participation of the family. In each treatment session there were warm-up exercises, neck-trunk stabilization exercises, and postural control exercises. Exercises were done in the pool 3 days a week; and especially stretching exercises were applied to the extremities that had spasticity for longer durations. Exercises to develop the fine motor skills were prescribed.

No adverse effects were observed aside from a slight pain in the waist area during sitting up on the 1st day after the application. After the six months intervention results listed in Table 1 and 2.

\section{Discussion}

Mesenchymal stem cell is a new and promising treatment option in treating anomalies like CP that appear in the muscle-skeleton system depending on the permanent damage in the brain whose development is still ongoing. This is safe in terms of carsinogenity and biosafety (12). After 4 applications and within 1 year follow-up, no systemic adverse effects were observed in our case and following the intrathecal application, no local side-effects were detected in our case aside from a one-day mild back pain. Wang et al. (13) reported no adverse effects aside from mild temperature. No serious adverse effects have been reported in subarachnoid, intramuscular and intravenous applications in the literature (13-15). It is possible to react the lesion directly with subarachnoid application, local in- 
tramuscular injection may show increasing effects in the muscle mass and functions due to the secretion of several neurotropic factors (16). Similarly, with intravenous application, increases were reported in the hind limb activity and improvements in muscle functions in dogs with spinal cord injuries. Furthermore, the cells were detected in the liver and in the injured spinal cord and in the spleen. This situation might show the increasing effect of MSC on the liver to tolerate exercise (17).

MSCs have the ability to renew themselves, and may differentiate into various mesenchymal tissues (18). In addition, they may have positive effects on the cognitive functions in the brain with neuro-protection and neuro-regeneration. Several studies suggest that hAECs can exert neuro-protection and facilitate neuron regeneration in cerebral diseases like stroke, Parkinsonism in animal models of CNS disorders (19).

Sankar and Muthusamy (20) reported positive effects of MSC in central and peripheral tissues. It has been reported in previous studies that in monkeys with spinal cord injuries, MSCs supported the growth of host axons, avoided glial scar formation, avoided death of neurons, and induced new collateral sprouting without any inflammation or rejection. It has also been reported that MSCs can secrete neurotropic factors which promoted neuronal recovery of the damaged cells in the brain. These factors could also promote the synaptogenesis to re-innervate the lost connections. In addition, since hAECs show pluripotent properties, they can differentiate into a neuronal phenotype and thus replace the damaged or dead cells (21). Furthermore, hAECs can also act as "biological minipumps" in the CNS thus secreting necessary cytokines, growth factors, hormones, and/or neurotransmitters to restore cellular function. As a last item, hAECs can also improve stroke outcome potentially by modulating the inflammatory response (which contributes to the brain injury $(21,22)$

In our case, we could not achieve any improvements in spasticity. Wang et al. reported improvements in muscle functions in cases that did not have any spasticity. There are several studies reporting obvious improvements in spasticity in some autologous MSC applications (21, 23).

In CP, application of UC-MSCs at earlier ages might bring higher achievement rates, which is also the case in any other treatment (24). An application that will be performed before complete neuron damage and joint contractures develop might increase the success of the treatment.

As a conclusion, we achieved improvements in cognitive skills, trunk control and hand skills; however, no improve- ments in spasticity. Future randomized-controlled and long-term studies may enlighten us on the superior sides and limitations of UC-MSCs Treatment.

\section{Acknowledgment}

We sincerely thanks Hande Başat, MD, and Physiotherapist Burcu Çaylı for their devoted rehabilitation treatment.

\section{Potential Conflict of Interest}

The authors have no conflicting financial interest.

\section{References}

1. Nelson KB. Can we prevent cerebral palsy? N Engl J Med 2003;349:1765-1769

2. Koman LA, Smith BP, Shilt JS. Cerebral palsy. Lancet 2004;363:1619-1631

3. Paneth N, Hong T, Korzeniewski S. The descriptive epidemiology of cerebral palsy. Clin Perinatol 2006;33:251-267

4. Lu D, Mahmood A, Wang L, Li Y, Lu M, Chopp M. Adult bone marrow stromal cells administered intravenously to rats after traumatic brain injury migrate into brain and improve neurological outcome. Neuroreport 2001;12:559-563

5. Longhi L, Zanier ER, Royo N, Stocchetti N, McIntosh TK. Stem cell transplantation as a therapeutic strategy for traumatic brain injury. Transpl Immunol 2005;15:143-148

6. Azari MF, Mathias L, Ozturk E, Cram DS, Boyd RL, Petratos S. Mesenchymal stem cells for treatment of CNS injury. Curr Neuropharmacol 2010;8:316-323

7. Friedenstein AJ, Gorskaja JF, Kulagina NN. Fibroblast precursors in normal and irradiated mouse hematopoietic organs. Exp Hematol 1976;4:267-274

8. Ichim TE, Solano F, Lara F, Paris E, Ugalde F, Rodriguez JP, Minev B, Bogin V, Ramos F, Woods EJ, Murphy MP, Patel AN, Harman RJ, Riordan NH. Feasibility of combination allogeneic stem cell therapy for spinal cord injury: a case report. Int Arch Med 2010;3:30

9. Han H, Chang SK, Chang JJ, Hwang SH, Han SH, Chun BH. Intrathecal injection of human umbilical cord blood-derived mesenchymal stem cells for the treatment of basilar artery dissection: a case report. J Med Case Rep 2011;5:562

10. Purandare C, Shitole DG, Belle V, Kedari A, Bora N, Joshi M. Therapeutic potential of autologous stem cell transplantation for cerebral palsy. Case Rep Transplant 2012; 2012:825289

11. Lee AS, Tang C, Rao MS, Weissman IL, Wu JC. Tumorigenicity as a clinical hurdle for pluripotent stem cell therapies. Nat Med 2013;19:998-1004

12. Phermthai T, Thongbopit S, Pokathikorn P, Wichitwiengrat S, Julavijitphong S, Tirawanchai N. Carcinogenicity, efficiency and biosafety analysis in xeno-free human amniotic stem cells for regenerative medical therapies. Cytotherapy 2017;19:990-1001 
13. Wang L, Ji H, Zhou J, Xie J, Zhong Z, Li M, Bai W, Li N, Zhang Z, Wang X, Zhu D, Liu Y, Wu M. Therapeutic potential of umbilical cord mesenchymal stromal cells transplantation for cerebral palsy: a case report. Case Rep Transplant 2013;2013:146347

14. Mehta T, Feroz A, Thakkar U, Vanikar A, Shah V, Trivedi H. Subarachnoid placement of stem cells in neurological disorders. Transplant Proc 2008;40:1145-1147

15. Rengasamy M, Gupta PK, Kolkundkar U, Singh G, Balasubramanian S, SundarRaj S, Chullikana A, Majumdar AS. Preclinical safety \& toxicity evaluation of pooled, allogeneic human bone marrow-derived mesenchymal stromal cells. Indian J Med Res 2016;144:852-864

16. Cruz-Martinez P, Pastor D, Estirado A, Pacheco-Torres J, Martinez S, Jones J. Stem cell injection in the hindlimb skeletal muscle enhances neurorepair in mice with spinal cord injury. Regen Med 2014;9:579-591

17. Kim Y, Jo SH, Kim WH, Kweon OK. Antioxidant and anti-inflammatory effects of intravenously injected adipose derived mesenchymal stem cells in dogs with acute spinal cord injury. Stem Cell Res Ther 2015;6:229

18. Wei CC, Lin AB, Hung SC. Mesenchymal stem cells in regenerative medicine for musculoskeletal diseases: bench, bedside, and industry. Cell Transplant 2014;23:505-512

19. Snyder EY, Yoon C, Flax JD, Macklis JD. Multipotent neu- ral precursors can differentiate toward replacement of neurons undergoing targeted apoptotic degeneration in adult mouse neocortex. Proc Natl Acad Sci U S A 1997;94:1166311668

20. Sankar V, Muthusamy R. Role of human amniotic epithelial cell transplantation in spinal cord injury repair research. Neuroscience 2003;118:11-17

21. Lindvall O, Kokaia Z. Recovery and rehabilitation in stroke: stem cells. Stroke 2004;35(11 Suppl 1):2691-2694

22. Broughton BR, Lim R, Arumugam TV, Drummond GR, Wallace EM, Sobey CG. Post-stroke inflammation and the potential efficacy of novel stem cell therapies: focus on amnion epithelial cells. Front Cell Neurosci 2013;6:66

23. Vaquero J, Zurita M, Rico MA, Bonilla C, Aguayo C, Fernández C, Tapiador N, Sevilla M, Morejón C, Montilla J, Martínez F, Marín E, Bustamante S, Vázquez D, Carballido J, Rodríguez A, Martínez P, García C, Ovejero M, Fernández MV; Neurological Cell Therapy Group. Repeated subarachnoid administrations of autologous mesenchymal stromal cells supported in autologous plasma improve quality of life in patients suffering incomplete spinal cord injury. Cytotherapy 2017;19:349-359

24. Goldstein M. The treatment of cerebral palsy: what we know, what we don't know. J Pediatr 2004;145(2 Suppl): S42-S46 